\title{
Gender Differences in the Polysomnographic Findings among Obstructive Sleep Apnea Patients
}

\author{
Lae Hyung Lee, Seung Ju Lee and Hyun Woo Kang \\ Department of Otolaryngology-Head and Neck Surgery, College of Medicine, Eulji University, Seoul, Korea
}

\author{
폐쇄성 수면 무호흡 환자에서 수면 다원 검사 결과의 성별 차이 \\ 이래형 · 이승주 · 강현우 \\ 을지대학교 의과대학 을지병원 이비인후-두경부외과학교실
}

Received November 30, 2011

Revised January 4, 2012

Accepted January 6, 2012

Address for correspondence

Seung Ju Lee, MD

Department of Otolaryngology

Head and Neck Surgery,

College of Medicine,

Eulji University,

14 Hangeulbiseok-gil, Nowon-gu,

Seoul 139-872, Korea

Tel $+82-2-970-8276$

Fax $+82-2-970-8275$

E-mail entdoc@eulji.ac.kr
Background and Objectives The aim of this study was to investigate the influence of gender on the polysomnographic differences between men and women with obstructive sleep apnea (OSA).

Subjects and Method A retrospective review was performed of 110 patients who snore (91 males, 19 females) and were suspected of OSA. Polysomnography was performed for each patient. Gender comparison of polysomnographic parameters were made by performing MannWhitney U-tests.

Results OSA was observed about five times more often in men than in women. Women were significantly older but were not heavier than men. Sleep structure showed no significant differences between men and women except that stage 1 sleep was observed more in men and stage 2 sleep more in women, respectively. The apnea hypopnea index (AHI) and non-rapid eye movement sleep were higher in men, but rapid eye movement sleep AHI in women was not different to men. The total and respiratory arousal indices (AI) and oxygen desaturation index (ODI) were higher in men than in women.

Conclusion The fact that more stage 1 sleep and the greater AHI, AI and ODI were found in men suggest that sleep quality may be worse in men than in women patients.

Korean J Otorhinolaryngol-Head Neck Surg 2012;55:90-4

Key Words Obstructive sleep apnea - Gender · Polysomnography.
서 론

폐쇄성 수면 무호흡(obstructive sleep apnea, OSA)은 주로 중년 이후의 남성에서 호발하며, 중년의 일반인에서는 유병률 의 남녀비가 대략 $2: 1$ 에서 $4: 1$ 정도로 보고되고 있으나, 수 면 클리닉에 내원하는 환자를 대상으로 한 경우에는 $8: 1$ 까지 도 차이가 난다.1) 남성에서 OSA의 유병률이 높은 이유는 아직 완벽하게 규명되지는 않았지만, 우선 성별에 따른 체지방 분포 의 차이가 원인이 될 수 있다. 여성의 체지방이 주로 둔부와 다리에 분포하는 데 반해, 남성의 경우 주로 복부와 목에 분 포하는 체지방이 OSA를 악화시킬 수 있다. 또 남성의 인두 기
도가 여성보다 길어서 찌그러지기 쉽다는 해부학적인 차이도 원인일 수 있다. ${ }^{2)}$ 그밖에 여성들의 비전형적인 증상, 사회문화 적 요인, 여성 호르몬의 역할 등이 언급되고 있다. ${ }^{2-4)}$

OSA가 있는 여성은 유병률뿐만 아니라 OSA의 호발 연령 과 비만도, 수면 다원 검사(polysomnography, PSG)에서의 수 면의 구조와 OSA의 중증도에서도 OSA가 있는 남성과는 다 른 양상을 보인다고 한다. 하지만 이에 대한 연구는 많지 않으 며, 최근 싱가포르인, 브라질인, 그리스인, 사우디인을 대상으로 PSG 결과의 성별 차이에 대한 연구 결과가 각각 발표되었으 나, ${ }^{1,5-8)}$ 상당한 차이점을 보이고 있어서, 일관된 결론을 얻을 수 없다. 더욱이 국내의 OSA 환자를 대상으로 PSG에서의 수 
면의 구조나 각 변수들의 성별 차이에 대한 포괄적인 연구는 되어있지 않다. 따라서 본 연구에서는 이비인후과의 수면 클리 닉을 방문한 환자들을 대상으로 연령과 비만도 및 PSG 결과가 어떠한 성별 차이를 보이는지 연구해보고자 하였다.

\section{대상 및 방법}

2008년 1월부터 2011년 7월까지 임상적으로 OSA가 의심되 는 코골이를 주소로 이비인후과의 수면 클리닉을 방문한 환자 들을 대상으로 후향적 연구를 시행하였다. PSG에서 apnea hypopnea intex(AHI)가 5 미만이거나, 수면 효율이 70\% 미만 인 환자를 제외한 110 명의 연속적인 환자를 연구 대상에 포함 시켰다. 연구에 포함된 환자들의 나이, 성별, 체질량 지수(body mass index, BMI), 주간 기면 지수(Epworth Sleepiness Scale, $\mathrm{ESS}$ ) 점수, $\mathrm{PSG}$ 의 변수 등에 대한 정보를 수집하였다. 기면증 (narcolepsy), 과다 수면(hypersomnolence), 주기성 사지 운동 장애(periodic limb movement disorder), 비만성 저환기 증후 군(obesity hypoventilation syndrome)으로 의심되는 환자들 은 제외하였고, 정신과적, 신경과적 이상이나 다른 전신적 질환 이 동반된 환자도 제외하였다. 이 연구를 위하여 환자의 자료 를 이용하는 것에 대해 임상시험심사위원회로부터 승인을 받 았다.

각 환자의 ESS 점수는 한국형 ESS 설문지를 사용하여 환자 와의 면담을 통해 평가하였다.9) 본원의 수면 검사실에서 검사 자에 의해 야간 PSG(A10, S7000; Embla, Denver, CO, USA) 를 시행하였다. 뇌파(C4/A1, O2/A1, F4/A1, F3/A2), 안전도, 심 전도, 비강 캐뉼라(nasal cannula)나 온도 측정기(thermal sensors)를 이용하여 측정한 구비강 호흡 기류(oronasal airflow), 맥박 산소 측정(pulse oxymetry), 복강과 흥곽의 움직임, 하악 과 하지의 근전도, 코골이 시간 등을 측정하였다.

수면 단계는 미국수면의학학회의 지침이에 따라 구분하였 다. 각 수면 단계가 차지하는 시간의 비율은 총 수면 시간에 대한 백분율로 표시하였다. 무호흡은 적어도 10 초 이상 호흡 기 류가 $90 \%$ 이상 감소하는 것으로, 저호흡은 적어도 10초 이상 호흡기류가 $30 \%$ 이상 감소하고 산소 포화도가 $4 \%$ 이상 저하 되는 경우로 정의하였다. $\mathrm{AHI}$ 는 총 수면 시간 중 한 시간당 무호흡과 저호흡 횟수의 합으로 정의하였다. 급속 안구 운동 (rapid eye movement, REM) 수면, 비급속 안구 운동(nonrapid eye movement, NREM) 수면 동안의 AHI도 각각 구하 였다.

코골이 시간의 비율은 코를 곤 시간을 총 수면 시간으로 나 누어 백분율로 표시하였다. 전등을 끈 후 1단계 수면과 REM 수면이 나타날 때까지 걸린 시간을 각각 수면 잠복기, REM 잠 복기로 정의하였다. 수면 효율은 총 수면 시간을 총 기록 시간 으로 나누어 백분율로 계산하였다. 각성은 미국수면장애학회 (American Sleep Disorders Association)에서 정의한 대로 분 류하여, ${ }^{11)}$ 총 수면시간 중 한 시간당 나타난 호흡 각성 지수와 총 각성 지수를 구하였다. 산소 탈포화 지수(oxygen desaturation index, ODI)는 총 수면 시간 중 한 시간당 산화 헤모글로 빈(oxyhemoglobin)의 탈포화(desaturation)가 $4 \%$ 이상 발생한 횟수로 정의하였다. 최저 산소 포화도(minimum pulse oxygen saturation, minimum $\mathrm{SpO}_{2}$ ) 및 산소 포화도가 $90 \%$ 미만인 시간의 길이(time length of $\mathrm{SpO}_{2}<90 \%$ )도 측정하였다.

통계 분석은 SPSS 12.0(SPSS Inc., Chicago, IL, USA)을 이 용하여 시행하였다. 남성과 여성, 두 군의 결과를 평균ㅍ표준편 차로 표시한 후 Mann-Whitney U-test를 시행하였다. 통계의 유의성은 유의확률 0.05 미만을 기준으로 하였다.

\section{결 과}

110 명의 환자 중 남성이 91명(82.7\%) 여성이 19명(17.3\%)이었 고 남녀비는 $4.8: 1$ 이었다. 환자의 평균 나이는 $42.6 \pm 12.8$ 세였 으며 18 세에서 78 세까지 분포하였다. 여성의 평균 나이는 49.4 \pm 12.1 세로 남성의 평균 나이 $41.2 \pm 12.6$ 세보다 의미 있게 높

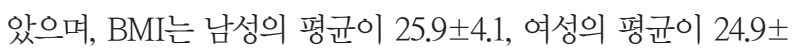
5.0 으로 성별 차이를 보이지 않았다. 설문에 답하지 않은 4명을 제외한 남성 89 명, 여성 17 명의 $\mathrm{ESS}$ 점수의 평균은 각각 $9.1 \pm$ 4.1, 9.1 \pm 4.5로 성별 차이를 보이지 않았다(Table 1).

PSG 결과에서 수면의 구조에 대한 변수의 성별 차이를 Table 2 에 제시하였다. 총 수면 시간은 남성에서 $404.5 \pm 75.1$ 분, 여성에 서 $406.9 \pm 36.2$ 분으로 차이를 보이지 않았다. 1단계 수면의 분 율은 남성에서 $23.8 \pm 12.0 \%$ 로 여성의 $16.4 \pm 10.9 \%$ 보다 의미 있 게 높았다. 반면 2단계 수면의 분율은 여성에서 $48.2 \pm 12.6 \%$ 로 남성의 $41.9 \pm 11.7 \%$ 보다 의미 있게 높았다. 1 단계와 2단계

Table 1. Demographic characteristics of obstructive sleep apnea patients

\begin{tabular}{lcccc}
\hline & Total $(\mathrm{n}=110)$ & Men $(\mathrm{n}=91)$ & Women $(\mathrm{n}=19)$ & p-value \\
\hline Age (years) & $42.6 \pm 12.8$ & $41.2 \pm 12.6$ & $49.4 \pm 12.1$ & $0.005^{*}$ \\
BMI $\left(\mathrm{kg} / \mathrm{m}^{2}\right)$ & $25.7 \pm 4.2$ & $25.9 \pm 4.1$ & $24.9 \pm 5.0$ & 0.158 \\
ESS score & $9.1 \pm 4.2(\mathrm{n}=106)$ & $9.1 \pm 4.1(\mathrm{n}=89)$ & $9.1 \pm 4.5(\mathrm{n}=17)$ & 0.638 \\
\hline
\end{tabular}

$* p<0.05$. BMI: body mass index, ESS: Epworth Sleepiness Scale 
를 합친 값은 성별 차이를 보이지 않았다. 서파 수면, REM 수 면, 각성기의 분율은 성별 차이를 보이지 않았다. 수면 잠복기, $\mathrm{REM}$ 잠복기, 수면 효율, 코골이 시간의 비율도 남녀간의 차이 를 보이지 않았다.

PSG 결과에서 호흡에 대한 변수의 성별 차이를 Table 3에 제시하였다. 남성의 AHI는 42.3 \pm 23.9 로, 여성의 27.2 \pm 21.6 보 다 의미 있게 높았다. NREM 수면시에도 남성의 AHI가 여성 보다 높았으나, REM 수면 동안에는 여성의 AHI가 $36.4 \pm 18.7$ 로 높아져서 남성의 $41.2 \pm 23.1$ 과 차이를 보이지 않았다. 호흡 각 성 지수와 총 각성 지수는 남성에서 29.8 $\pm 21.0,34.7 \pm 19.8$ 로 여 성의 $16.2 \pm 16.4,23.8 \pm 16.4$ 보다 높았다. ODI는 남성에서 $31.6 \pm$ 23.5로 여성의 18.6 \pm 19.3 보다 높았고 최저 산소 포화도는 차이 가 없었다. 산소 포화도가 $90 \%$ 미만인 시간의 길이는 남성에 서 28.4 446.4 분으로 여성의 $10.6 \pm 15.2$ 분보다 높았으나 통계에 서 유의한 차이를 보이지는 않았다.

\section{고 찰}

OSA의 유병률의 남녀비는 연구 대상에 따라서 $1.9: 1$ 에서 $8.7: 1$ 의 광범위한 분포를 보였다., ${ }^{1,-8)} \mathrm{PSG}$ 를 통해 OSA로 진단 받은 1010 명의 그리스인을 대상으로 한 연구에서 OSA의 유병
률의 남녀비가 $5: 1$ 이었는데, 본 연구에서도 이와 비슷한 $4.8: 1$ 의 비율로 남성 OSA 환자가 더 많았다. ${ }^{1)}$

OSA가 있는 경우 성별에 따라 수면의 구조가 다르다고 한다.12) 남성에 비해 여성의 수면 잠복기가 길고, ${ }^{1,5-7)}$ 수면 효율이 낮으 며 각성기가 늘어나서, ${ }^{1,5)}$ 그리스인 여성 OSA 환자에서 불면증 이 빈발하고 수면의 질이 남성보다 나쁘다는 보고가 있었다. 반 면 OSA가 있는 싱가포르인과 브라질인 남성에서 얕은 수면인 1,2 단계 수면이, 여성에서는 깊은 수면인 3, 4단계 수면이 의 미 있게 많았다.67) 본 연구에서는 수면 잠복기, 수면 효율, 얕은 수면과 깊은 수면의 분율 모두 성별 차이를 보이지 않았으나 입 면기인 1단계 수면은 남성에서, 경수면기인 2단계 수면은 여성 에서 의미 있게 많았다. 이것은 본 논문에서 처음 발표되는 소견으로서, 남성의 수면이 여성에 비해 2단계로 진행하지 못 하고 입면기인 1 단계에 머무는 비율이 높다는 것을 의미한다 고 생각된다.

본 연구에서 남성은 여성보다 높은 $\mathrm{AHI}$ 와 각성 지수를 보여 서 훨씬 심한 OSA가 있다고 생각된다. PSG의 호흡 변수의 성 별 차이에 대해서는 대부분의 연구자들이 비교적 일관된 결과 를 제시하고 있다.15-7,13,14) 남성이 주로 NREM 수면기에 좀 더 심 한 정도의 OSA를 보이는 것에 비하여,1,5, 여성은 REM 수면기에 호흡 사건(respiratory events)이 밀집되는 경한 OSA를 보인다고

Table 2. Comparison of sleep parameters obtained by polysomnography between genders

\begin{tabular}{lcccc}
\hline \multicolumn{1}{c}{ Parameters } & Total $(\mathrm{n}=110)$ & Men $(\mathrm{n}=91)$ & Women $(\mathrm{n}=19)$ & $\mathrm{p}$-value \\
\hline Total sleep time (min) & $404.9 \pm 69.8$ & $404.5 \pm 75.1$ & $406.9 \pm 36.2$ & 0.800 \\
Stage 1 (\%) & $22.6 \pm 12.1$ & $23.8 \pm 12.0$ & $16.4 \pm 10.9$ & $0.007^{*}$ \\
Stage 2 (\%) & $43.0 \pm 12.1$ & $41.9 \pm 11.7$ & $48.2 \pm 12.6$ & $0.047^{*}$ \\
Stage 1+Stage 2(\%) & $65.5 \pm 7.5$ & $65.8 \pm 7.7$ & $64.5 \pm 6.4$ & 0.457 \\
Stage 3 (\%) & $5.5 \pm 4.7$ & $5.3 \pm 4.7$ & $6.4 \pm 4.9$ & 0.273 \\
REM sleep (\%) & $17.5 \pm 11.5$ & $17.5 \pm 12.4$ & $17.3 \pm 4.9$ & 0.436 \\
Wake state (\%) & $12.6 \pm 7.9$ & $12.7 \pm 7.9$ & $11.8 \pm 7.9$ & 0.512 \\
Sleep latency (min) & $8.2 \pm 11.8$ & $8.3 \pm 12.7$ & $7.8 \pm 5.8$ & 0.294 \\
REM latency (min) & $121.9 \pm 64.7$ & $120.4 \pm 66.5$ & $129.0 \pm 56.0$ & 0.297 \\
Sleep efficiency (\%) & $86.4 \pm 7.9$ & $86.3 \pm 7.9$ & $86.8 \pm 7.9$ & 0.740 \\
Percentage of snoring time (\%) & $71.5 \pm 24.9$ & $72.4 \pm 25.0$ & $66.9 \pm 24.4$ & 0.272 \\
\hline
\end{tabular}

$* p<0.05$. REM: rapid eye movement

Table 3. Comparison of respiratory parameters obtained by polysomnography between genders

\begin{tabular}{lcccc}
\hline \multicolumn{1}{c}{ Parameters } & Total $(\mathrm{n}=110)$ & Men $(\mathrm{n}=91)$ & Women $(\mathrm{n}=19)$ & p-value \\
\hline AHI $\left(\mathrm{h}^{-1}\right)$ & $39.7 \pm 24.1$ & $42.3 \pm 23.9$ & $27.2 \pm 21.6$ & $0.011^{*}$ \\
Non REM AHI $\left(\mathrm{h}^{-1}\right)$ & $39.4 \pm 26.2$ & $42.4 \pm 25.9$ & $24.8 \pm 23.0$ & $0.006^{*}$ \\
REM AHI $\left(\mathrm{h}^{-1}\right)$ & $40.3 \pm 22.4$ & $41.2 \pm 23.1$ & $36.4 \pm 18.7$ & 0.422 \\
Respiratory arousal index $\left(\mathrm{h}^{-1}\right)$ & $27.5 \pm 20.8$ & $29.8 \pm 21.0$ & $16.2 \pm 16.4$ & $0.004^{*}$ \\
Total arousal index $\left(\mathrm{h}^{-1}\right)$ & $32.8 \pm 19.6$ & $34.7 \pm 19.8$ & $23.8 \pm 16.4$ & $0.018^{*}$ \\
Oxygen desaturation index $\left(\mathrm{h}^{-1}\right)$ & $29.4 \pm 23.3$ & $31.6 \pm 23.5$ & $18.6 \pm 19.3$ & $0.020^{*}$ \\
Minimum $\mathrm{SpO}_{2}(\%)$ & $80.8 \pm 8.1$ & $80.4 \pm 46.3$ & $82.4 \pm 5.9$ & 0.521 \\
Time length of $\mathrm{SpO}_{2}<90 \%(\mathrm{~min})$ & $25.3 \pm 43.1$ & $28.4 \pm 46.4$ & $10.6 \pm 15.2$ & 0.135 \\
\hline
\end{tabular}

$* p<0.05$. AHI: apnea-hypopnea index, REM: rapid eye movement 
한다. ${ }^{1,15)}$ 본 연구에서도 NREM 수면기에는 남성의 AHI가 여성 보다 높았으나, REM 수면기에는 여성의 AHI가 증가하여 남성 의 $\mathrm{AHI}$ 와 거의 차이를 보이지 않았다.,5,6) 여성의 호흡 사건이 $\mathrm{REM}$ 수면기에 더 많은 이유는 아직 밝혀지지 않았으나, 이설 근을 통하여 기도를 보호하는 여성 호르몬의 효과가 REM 수 면 중 없어지는 것이 원인으로 생각된다. ${ }^{16)}$ 이러한 PSG의 호흡 변수의 성별 차이와 함께 1 단계 수면이 남성에서 의미 있게 증 가하였다는 점을 고려한다면, 본 연구에 포함된 한국인에서는 그리스인에서와는 반대로 남성 수면의 질이 여성보다 떨어져 있 을 가능성이 있다고 생각된다.

대부분의 연구 결과와 마찬가지로 본 연구에서도 최저 산소 포화도는 성별 차이가 없었다. ${ }^{1,5,6,8)}$ 하지만 남성의 ODI가 여성 보다 높았으며, 산소 포화도가 $90 \%$ 미만인 시간의 길이가 통계 적인 의미는 없으나 남성에서 길었다. 이러한 소견들은 앞에서 기술한 것처럼 남성에서 OSA의 정도가 더 심하다는 사실을 반 영하는 것으로 생각된다.

대부분의 연구에서 OSA 환자의 평균 연령이 남성은 40대, 여성은 50 대였으며, ${ }^{5,8,17)}$ 본 연구에서도 비슷한 결과를 보였다. 여성의 경우 프로게스테론과 같은 호르몬이 수면의 조절에 중 요한 역할을 하여, 폐경 전 여성의 호흡을 자극시키고 이설근 의 활동을 증가시켜서 수면 중에 인두 기도가 찌그러지는 것 을 막아주어 OSA의 발병에서 여성을 보호해 준다고 한다. ${ }^{18)}$ 따라서 폐경 이후에는 성호르몬이 감소하여 여성의 OSA가 증 가할 수 있으므로 여성에서는 남성보다 10년 정도 늦게 OSA 가 발병할 수 있다고 생각된다. ${ }^{1,19}$

$\mathrm{BMI}$ 가 남성 또는 여성 환자에서 더 높았다는 연구 결과가 있었지만,5) 본 연구에서는 다른 연구들의 결과와 마찬가지로 남녀 간에 차이를 보이지 않았다. $1,6,8)$ 나이가 많은 여성은 OSA 가 있더라도 비만의 정도가 덜하고, 나이가 젊은 여성 OSA 환 자는 비만한 경우가 많다는 연구 결과가 있었다. ${ }^{12)}$ 본 연구에서 는 2 명을 제외한 모든 환자가 40 세 이상이어서 여성에서 비만 의 정도가 덜하였을 수 있다. OSA 환자의 BMI 평균값이 30 $\mathrm{kg} / \mathrm{m}^{2}$ 이상인 연구 결과가 많았는데, ${ }^{1,5,8,15)}$ 본 연구에 포함된 $\mathrm{OSA}$ 환자의 평균 $\mathrm{BMI}$ 는 가장 낮은 결과를 보인 싱가포르인 의 BMI 중앙값인 $26.8 \mathrm{~kg} / \mathrm{m}^{2}$ 보다 더 낮은 $25.1 \mathrm{~kg} / \mathrm{m}^{2}$ 이었 다. ${ }^{6}$ 따라서 한국인 OSA 환자는 다른 인종의 환자보다 덜 비 만하다고 생각되며, 비만 단계 이전의 과체중 단계에서도 OSA 가 발견될 가능성이 상당하다고 생각된다.

연구에 포함된 환자들의 수가 적고, 유병률의 남녀 차이로 인 하여 다양한 연령대의 여성 환자가 포함되지 못하였으며, 남녀 의 연령차가 PSG 결과의 성별 차이에 영향을 끼칠 수 있었다는 점이 본 연구의 한계점이다. 하지만 연령에 의한 영향을 배제 하기 위하여 40 세 이상의 남성 환자 51 명과 여성 환자 17 명만
을 대상으로 하여 PSG 결과의 성별 차이를 분석해 본 경우에 도 비슷한 양상을 볼 수 있었다. 한 가지 다른 결과는 성별 차이 가 나지 않았던 서파 수면의 분율이 여성에서 의미 있게 높았 다는 점이었다.

본 연구에서 저자들은 국내의 OSA 환자를 대상으로 PSG 결 과에서 중요한 성별 차이를 확인하였다. 여성 환자들의 평균 나 이가 남성보다 많았으나, $\mathrm{BMI}$ 는 성별 차이가 없었다. 수면의 구 조는 남녀 간에 큰 차이가 없었으나 남성에서 1단계, 여성에서 2단계 수면이 많았다. 남성 환자의 $\mathrm{AHI}$, 각성 지수, ODI가 여성 보다 높아서 남성 환자의 OSA의 정도가 더 심하고 수면의 질이 떨어져 있을 가능성이 있다고 생각된다.

\section{REFERENCES}

1) Vagiakis E, Kapsimalis F, Lagogianni I, Perraki H, Minaritzoglou A, Alexandropoulou K, et al. Gender differences on polysomnographic findings in Greek subjects with obstructive sleep apnea syndrome. Sleep Med 2006;7(5):424-30.

2) Lin CM, Davidson TM, Ancoli-Israel S. Gender differences in obstructive sleep apnea and treatment implications. Sleep Med Rev 2008; 12(6):481-96.

3) Ryan CM, Bradley TD. Pathogenesis of obstructive sleep apnea. J Appl Physiol 2005;99(6):2440-50.

4) Shepertycky MR, Banno K, Kryger MH. Differences between men and women in the clinical presentation of patients diagnosed with obstructive sleep apnea syndrome. Sleep 2005;28(3):309-14.

5) Alotair H, Bahammam A. Gender differences in Saudi patients with obstructive sleep apnea. Sleep Breath 2008;12(4):323-9.

6) Lim LL, Tham KW, Fook-Chong SM. Obstructive sleep apnoea in Singapore: polysomnography data from a tertiary sleep disorders unit. Ann Acad Med Singapore 2008;37(8):629-36.

7) Silva A, Andersen ML, De Mello MT, Bittencourt LR, Peruzzo D, Tufik S. Gender and age differences in polysomnography findings and sleep complaints of patients referred to a sleep laboratory. Braz J Med Biol Res 2008;41(12):1067-75.

8) Knorst MM, Souza FJ, Martinez D. [Obstructive sleep apnea-hypopnea syndrome: association with gender, obesity and sleepiness-related factors]. J Bras Pneumol 2008;34(7):490-6.

9) Cho YW, Lee JH, Son HK, Lee SH, Shin C, Johns MW. The reliability and validity of the Korean version of the Epworth sleepiness scale. Sleep Breath 2011;15(3):377-84.

10) Iber C, Ancoli-Israel S, Chesson A, Quan SF. The AASM Manual for the Scoring of Sleep and Associated Events: Rules, Terminology and Technical Specifications. 1st ed. Westchester, US: American Academy of Sleep Medicine; 2007.

11) ASDA. EEG arousals: scoring rules and examples: a preliminary report from the Sleep Disorders Atlas Task Force of the American Sleep Disorders Association. Sleep 1992;15(2):173-84.

12) Redline S, Kirchner HL, Quan SF, Gottlieb DJ, Kapur V, Newman A. The effects of age, sex, ethnicity, and sleep-disordered breathing on sleep architecture. Arch Intern Med 2004;164(4):406-18.

13) Dursunoglu N, Ozkurt S, Sarikaya S. Is the clinical presentation different between men and women admitting to the sleep laboratory? Sleep Breath 2009;13(3):295-8.

14) Gabbay IE, Lavie P. Age- and gender-related characteristics of obstructive sleep apnea. Sleep Breath 2011; [Epub ahead of print].

15) O'Connor C, Thornley KS, Hanly PJ. Gender differences in the polysomnographic features of obstructive sleep apnea. Am J Respir Crit Care Med 2000;161(5):1465-72. 
16) Popovic RM, White DP. Influence of gender on waking genioglossal electromyogram and upper airway resistance. Am J Respir Crit Care Med 1995;152(2):725-31.

17) Young T, Finn L, Austin D, Peterson A. Menopausal status and sleepdisordered breathing in the Wisconsin Sleep Cohort Study. Am J Respir Crit Care Med 2003;167(9):1181-5.
18) Andersen ML, Bittencourt LR, Antunes IB, Tufik S. Effects of progesterone on sleep: a possible pharmacological treatment for sleepbreathing disorders? Curr Med Chem 2006;13(29):3575-82.

19) Netzer NC, Eliasson AH, Strohl KP. Women with sleep apnea have lower levels of sex hormones. Sleep Breath 2003;7(1):25-9. 